Jurnal Informatika dan Rekayasa Perangkat Lunak (JATIKA)
Vol. 1, No. 1, June 2020, page-page. 51 57

\title{
RANCANG BANGUN GAME EDUKASI TEMPAT BERSEJARAH DI INDONESIA
}

\author{
Sanriomi Sintaro ${ }^{1}$, Rahmat Ramdani ${ }^{2}$, Slamet Samsugi ${ }^{3}$ \\ Universitas Teknokrat Indonesia ${ }^{1,2,3}$ \\ sanriomi@teknokrat.ac.id ${ }^{1}$,rahmatramadani@gmail.com ${ }^{1}$, s.samsugi@teknokrat.ac.id ${ }^{1}$

\begin{tabular}{lll}
\hline \hline Received: (Mei 2020) & Accepted: (Mei 2020) & Published: (Juni 2020 ) \\
\hline
\end{tabular}

\begin{abstract}
In today's society and especially among children it seems as if they do not care about the historical heritage left by the ancestors, for example is a historical building. In fact, many are not aware of the existence of these buildings. Ignorance of history will lead to the assumption that historic buildings need not be preserved, and only assume that the historic building is just an old building that is not suitable for use. Therefore, we need a media that can increase children's interest and knowledge about historic sites, based on this the authors conducted a study with the title "Educational Building Design of Historic Sites in Indonesia". This game was developed with the Game Development Life Cycle Method. Then to find out the feasibility of this game was tested using ISO 9126 with four aspects of testing, namely Functionality, Usability, Efficiency and Portability. Based on the evaluation of observations made to students in grades 5 and 6 MIN 7 Bandar Lampung, there was an increase in students' ability to answer questions about historic sites in Indonesia, especially those on the islands of Sumatra and Java contained in the game by 50\% of the initial conditions where students haven't played an educational game on historic sites in Indonesia.
\end{abstract}

Keywords: construct 2, educational game, history game, historical heritages in Indonesia, history game, game

\begin{abstract}
Abstrak
Kehidupan bermasyarakat dewasa ini dan khususnya untuk kalangan anak-anak terlihat seperti tidak peduli pada peninggalan sejarah yang ditinggalkan oleh para leluhur, contohnya adalah bangunan bersejarah. Bahkan banyak yang tidak mengetahui akan keberadaan bangunan-bangunan tersebut. Ketidaktahuan mengenai sejarah akan menyebabkan anggapan bahwa bangunan bersejarah tidak perlu di lestarikan, dan hanya menganggap bahwa bangunan bersejarah hanyalah sebuah bangunan tua yang tidak layak pakai. Maka dari itu diperlukan sebuah media yang dapat meningkatkan minat dan pengetahuan anak-anak mengenai tempat bersejarah, berdasarkan hal tersebut penulis melakukan penelitian dengan judul "Rancang Bangun Game Edukasi Tempat Bersejarah di Indonesia". Game ini dikembangkan dengan Metode Game Development Life Cycle. Kemudian untuk untuk mengetahui kelayakan Game ini diuji menggunakan ISO 9126 dengan empat aspek pengujian yaitu Functionality, Usability, Efficiency dan Portability. Berdasarkan evaluasi hasil observasi yang dilakukan terhadap siswa kelas 5 dan 6 MIN 7 Bandar Lampung terjadi peningkatan kemampuan siswa dalam menjawab soal tentang tempat bersejarah di Indonesia khususnya yang terdapat di Pulau Sumatera dan Pulau Jawa yang terdapat di dalam game sebesar $50 \%$ dari kondisi awal dimana siswa belum memainkan game edukasi tempat bersejarah di Indonesia.
\end{abstract}

Kata Kunci: construct 2, game game edukasi, , game sejarah, peninggalan bersejarah di Indonesia 
To cite this article:

Sanriomi Sintaro, Rahmat Ramdani, Slamet Samsugi. (2020). RANCANG BANGUN GAME EDUKASI TEMPAT BERSEJARAH DI INDONESIA. Jurnal Informatika dan Rekayasa Perangkat Lunak, Vol(1), 51-57.

\section{PENDAHULUAN}

Sejarah tidak akan pernah kembali terulang, begitu juga dengan peninggalan nya. Hal-hal yang terjadi di masa lalu akan menjadi kenangan yang dapat di kenang. salah satu cara mengenang masa lalu adalah dengan peninggalan yang masih tersisa. Begitu juga dengan peninggalan sejarah, yang tanpa disadari penginggalan tersebut dapat menceritakan sejarah mengenai masa keemasan yang pernah dilewatinya.

Di Indonesia sendiri yang merupakan wilayah kepulauan, banyak sekali peninggalan sejarah yang di wariskan kepada generasi yang baru, generasi yang mengharuskan penginggalan tersebut terus ada dan tidak dilupakan. Salah satu contoh peninggalan bersejarah adalah bangunan bangunan yang dibangun di jamannya. Berbagai bangunan bersejarah yang terdapat di Indonesia seperti Candi Borobudur di Yogjakarta, Istana Maimun di Medan, Lawang Sewu di Semarang, Gedung Sate di Bandung, dan berbagai bangunan lain yang menjadi landmark di daerahnya memiliki kisah dan cerita yang harus di wariskan.

Kehidupan bermasyarakat dewasa ini dan khususnya untuk kalangan anak-anak terlihat seperti tidak peduli pada peninggalan sejarah yang ditinggalkan oleh para leluhur, contohnya adalah bangunan bersejarah. Bahkan banyak yang tidak mengetahui akan keberadaan bangunan-bangunan tersebut. Ketidaktahuan mengenai sejarah akan menyebabkan anggapan bahwa bangunan bersejarah tidak perlu di lestarikan, dan hanya menganggap bahwa bangunan bersejarah hanyalah sebuah bangunan tua yang tidak layak pakai. (Vika dan Renaldi, 2015). Tujuan yang ingin dicapai dari penelitian ini adalah Tercapai membangun sebuah game edukasi tempat bersejarah di Indonesia, serta Menjadikan game sebagai media alternatif pembelajaran bagi anak-anak sehingga dapat menambah minat anak untuk mengenal cerita tempat bersejarah di Indonesia.

\section{TELAAH PUSTAKA}

\section{Permainan (Game)}

Menurut Wulandari (2012) Game di ambil dari kata dalam bahasa inggris yang berarti permainan. Suatu hal dapat dikatakan sebuah permainan jika hal tersebut dimainkan dengan menentukan aturan yang akan digunakan dalam permainan tersebut. Sedangkan Video Game adalah sebuah permainan yang dimainkan dengan menggunakan media elektronik, memiliki berbagai jenis Media seperti suara, gambar bergerak yang di buat sehingga menarik dan dapat memberi kepuasan batin kepada pemain yang memainkannya(Wulandari, 2012).

Sedangkan menurut Adams (2010) Game merupakan kegiatan bermain yang memiliki aktifitas dengan konteks tidak nyata namun terlihat seperti realistis, dimana pemain yang memainkannya memiliki tujuan akhir atau tujuan untuk memenangkan permainan dengan aturan-aturan tertentu yang dibuat untuk menyesuaikan dengan Game yang ada.

\section{Game Edukasi (Educational Game)}

Menurut Hurd dan Jennings (2009) Game edukasi merupakan sebuah game digital yang di buat untuk memperbanyak pengetahuan (dengan belajar mengajar) yang di buat dengan menggunakan teknologi dengan multimedia dan dirancang dengan baik sesuai kreteria dari edukasi yang diinginkan.

\section{Bangunan Bersejarah}

Presiden Republik Indonesia melalui UUD nomor 11 Tahun 2010 tentang Cagar Budaya, menimbang bahwa cagar budaya merupakan budaya bangsa yang menjadi kekayaan negara merupakan hasil dari pemikiran dan perilaku kehidupan, karena itu cagar budaya harus lah dilestarikan. 


\section{Finite Stage Machine (FSM)}

Menurut Nendya dkk (2015) FSM merupakan suatu pemodelan yang terbentuk atas prilaku dari sebuah system maupun obyek yang dirancang secara kompleks, sehingga memiliki kondisi, mode dan definisi yang berubah sesuai dengan keadaan.

\section{METODE PENELITIAN}

\section{Tahapan Penelitian}

Tahapan pemikiran merupakan bentuk dari keseluruan proses dalam penelitian. Diawali dengan identifikasi masalah, kemudian usulan solusi, dilanjutkan ke tahap pengembangan, mendapatkan hasil pembahasan dan kesimpulan.

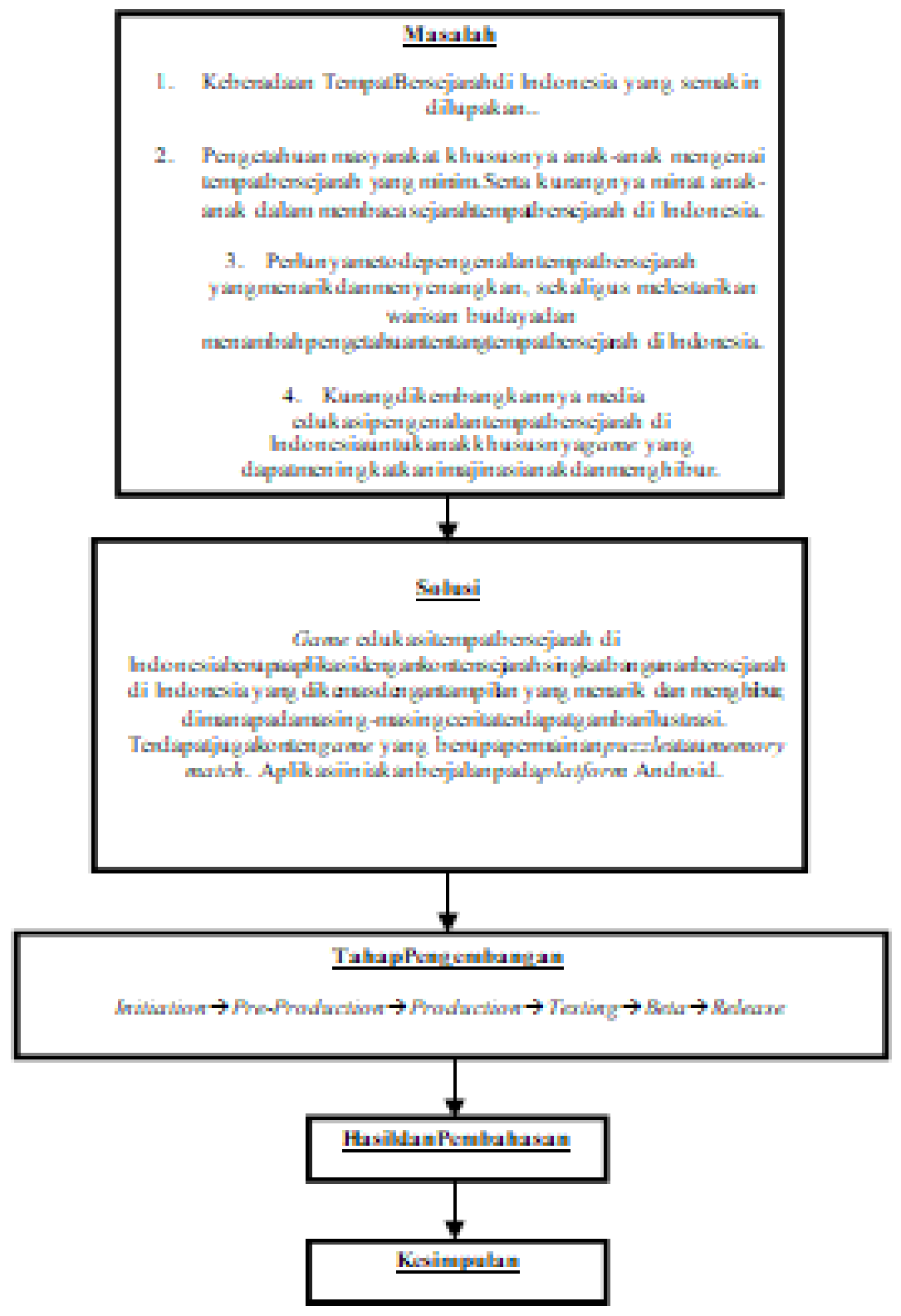

Gambar 1. Tahapan Penelitian 


\section{Teknik Pengumpulan Data}

Wawancara dilakukan kepada peserta didik untuk mengetahui apakah perserta didik memiliki pengetahuan mengenai tempat bersejarah, dan kuisoner digunakan untuk mendapatkan data atas aspek usabilitas.

\section{Metode Analisis}

Menggunakan Kuantitafif sebagai acuan untuk menganalisis kemudian menggunakan ISO 9126 untuk mengetahui usability, functionality, portability dan efficiency.

\section{HASIL DAN PEMBAHASAN}

Metode pengembangan GDLC memiliki 6 tahapan, 6 tahapan pada penelitian ini telah dilakukan secara berurutan dengan hasil yaitu sebagai berikut :

Initiation dilakukan dengan merancang konsep yang dapat dilihat pada tabel 1 dibawah ini.

\begin{tabular}{ccc}
\multicolumn{3}{c}{ Table 1. Konsep Initiation } \\
\hline Pengguna & Jenis Game & Materi \\
\hline Anak SD & Edukasi & Sejarah \\
\hline
\end{tabular}

PreProduction dilakukan dengan cara membuat gameplay, flowchar dan storyboard. Kemudian dilanjutkan dengan Production yang dilakukan berdasarkan tahapan pre-production sebelumnya, setelah itu dilakukan Testing untuk menguji game tersebut sudah dapat dimaikan atau belum. Setelah tahapan dirasa selesai maka dilakukan pengujian kelayakan dari game dengan hasil yang dapat dilihat pada table 2 dibawah ini.

\begin{tabular}{cl}
\multicolumn{2}{c}{ Table 2. Hasil Pengujian Game } \\
\hline Aspek & \multicolumn{1}{c}{ Hasil } \\
\hline Functionality & $\begin{array}{l}\text { Aplikasi dapat melakukan 100\% } \\
\text { fungsinya dengan benar atau } \\
\text { sangat baik }\end{array}$ \\
Usability & $\begin{array}{l}\text { Pengujian aspek usability } \\
\text { memperoleh nilai persentase }\end{array}$ \\
& sebesar 92.8\% \\
Portability & $\begin{array}{l}\text { Aplikasi dapat di-install dan } \\
\text { dijalankan pada device android }\end{array}$ \\
Efficiency & Tidak mengalami kekurangan \\
& memory yang dapat menyebabkan \\
& berhentinya penggunaan aplikasi \\
& (Force close).
\end{tabular}

Hasil dari implementasi design yang sudah dibuat menghasilkan tampilan yang dapat dilihat pada gambar dibawah ini.

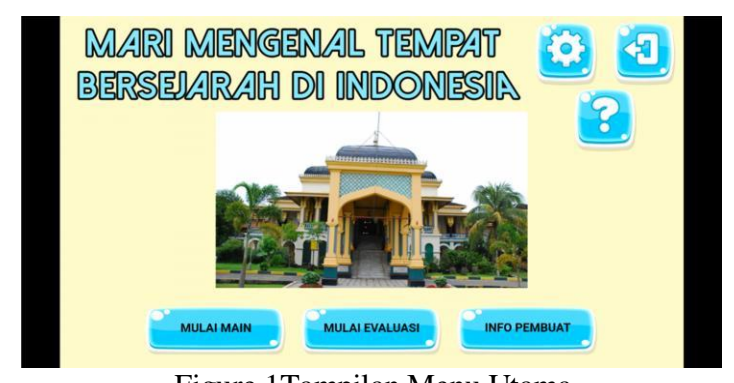

Figure 1Tampilan Menu Utama

Untuk memilih stage, dibutuhkan menu pemilihan stage dengan gambar peta Indonesia yang di berikan penanda daerah yang terbuka, Stege berikutnya akan terbuka jika peserta didik sudah menyelesaikan game pada stage sebelumnya, untuk dapat melihat hasil implementasinya dapat dilihat pada gambar 2 dibawah ini. 


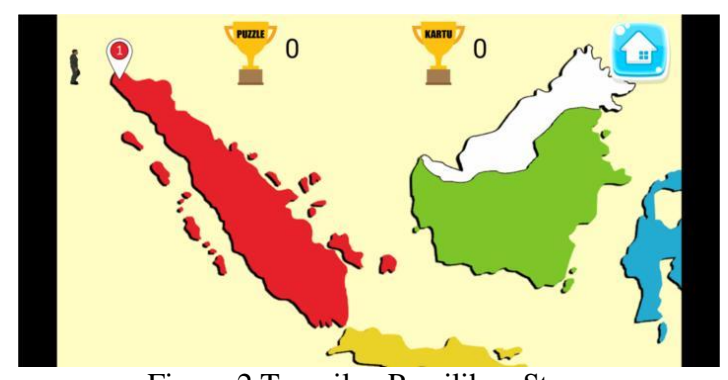

Figure 2 Tampilan Pemilihan Stage

Pada tampilan game puzzle pemain harus menyusun puzzle dengan benar sebelum 100 detik. Apabila potongan puzzle cocok akan terpasang dan mengeluarkan efek suara. Tampilan dapat dilihat pada gambar 3 dibawah ini.

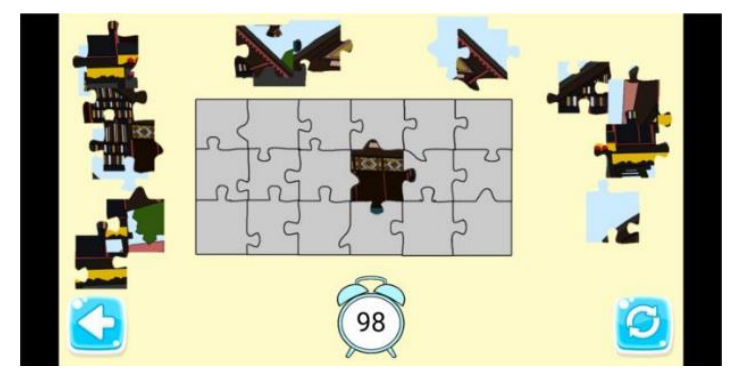

Figure 3. Tampilan Game Puzzle

Pada tampilan game ini pemain diminta untuk mencocokan 8 pasang gambar yang sama di balik kartu sebelum 60 detik. Apabila gambar cocok maka akan mengeluarkan efek suara. Untuk melihat tampilan game memory match dapat dilihat pada gambar 4 dibawah ini.

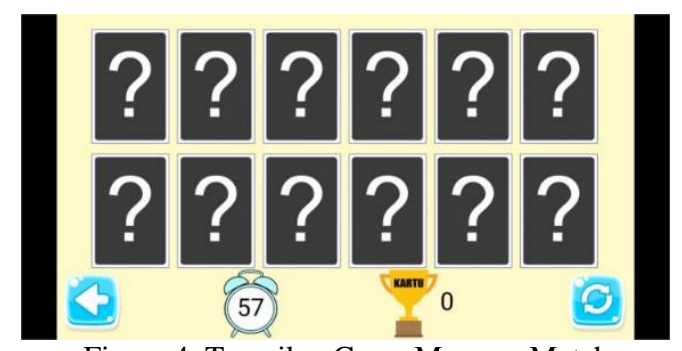

Figure 4. Tampilan Game Memory Match

Jika pemain berhasil menyelesaikan game puzzle dan memory match, maka akan muncul sejarah singkat bangunan tersebut. Untuk melihat tampilan sejarah singkat dapat dilihat pada gambar 5 dibawah ini.

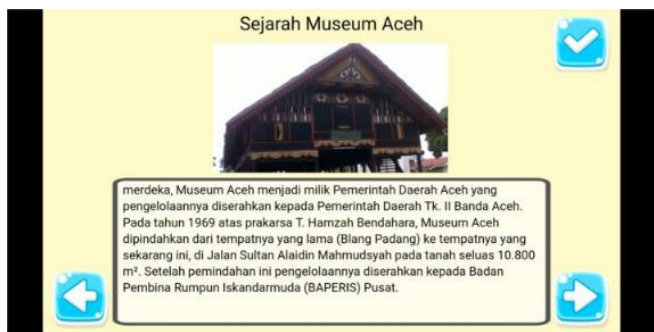

Figure 5. Tampilan Sejarah Singkat 
Pada tampilan ini terdapat kuis yang harus dijawab pertanyaannya oleh pemain, hal ini dimaksudkan agar mengetahui apakah informasi sejarah singkat sudah dicerna dengan baik oleh peserta didik. Tampilan dapat dilihat pada gambar 6 dibawah ini.

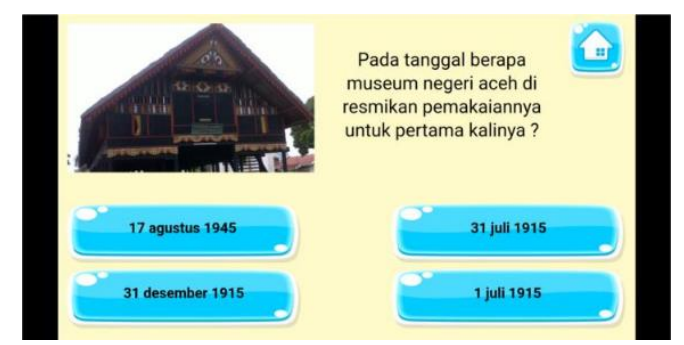

Figure 6. Tampilan Menu Evaluasi

\section{EVALUASI}

Hasil quisoner akhir mengenai tempat bersejarah untuk mengetahui tingkat pengetahuan peserta didik, quidoner ini berisikan ujian mengenai pengetahuan para peserta didik tentang tempat bersejarah di Indonesia yang dilakukan terhadap siswa sekolah dasar kelas 5 dan 6 MIN 7 Bandar Lampung. Pada quisoner ini diambil 50 sampel, responden diberikan 15 pertanyaan yang berisi tentang tempat bersejarah yang ada di Pulau Sumatera dan Pulau Jawa untuk mengetahui tingkat pengetahuan siswa sebelum memainkan game. Menghasilkan grafik pengetahuan yang dapat dilihat pada gambar dibawah ini.

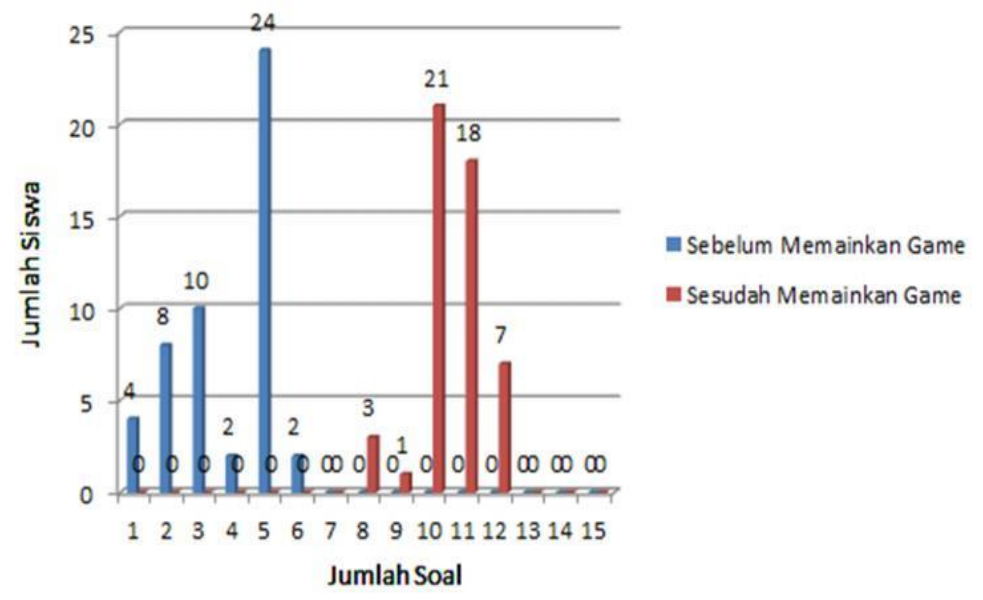

Figure 7. Grafik perbandingan

Berdasarkan gambar 7. dapat dilihat bahwa terjadi peningkatan jumlah siswa yang mampu menjawab soal dengan benar setelah siswa memainkan game edukasi tempat bersejarah di Indonesia. Sebelum siswa memainkan game edukasi tempat bersejarah di Indonesia, siswa hanya mampu menjawab soal sejumlah 1 sampai dengan 6 soal saja, dimana jumlah soal yang paling banyak mampu dijawan oleh siswa yaitu 5 soal.

Setelah siswa memainkan game edukasi tempat bersejarah di Indonesia, jumlah soal yang mampu dijawab oleh siswa mengalami peningkatan, dimana pada kondisi ini siswa mampu menjawab 8 sampai dengan 12 soal. Jumlah soal yang paling banyak mampu dijawab oleh siswa adalah 10 soal.

Grafik di atas menggambarkan bahwa terjadi peningkatan kemampuan siswa untuk menjawab soal dengan benar sebanyak $50 \%$ dari kondisi awal, dimana siswa belum memainkan game edukasi tempat bersejarah di Indonesia. Oleh karena itu, dapat disimpulkan bahwa game edukasi tempat bersejarah di Indonesia berpotensi meningkatkan pengetahuan mengenai tempat bersejarah di Indonesia khususnya tempat bersejarah yang ada di Pulau Sumatera dan Pulau Jawa seperti yang ada di dalam game. 


\section{SIMPULAN}

Telah dibangun sebuah game edukasi tempat bersejarah di Indonesia, sebagai media alternatif / tambahan yang menarik dan menyenangkan agar dapat meningkatkan minat mengetahui tempat bersejarah di Indonesia menggunakan platform android. Metode pengembangan game development life cycle dengan 6 (enam) tahapan yaitu Initiation, Pre-Production, Production, Testing, Beta, Release. Hasil dari pengujian 4 aspek ISO 9126 (usability, functionality, portability dan efficiency) pada aplikasi game edukasi tempat bersejarah di Indonesia menunjukkan bahwa aplikasi tersebut layak digunakan.

Berdasarkan hasil evaluasi observasi yang dilakukan kepada 50 siswa kelas 5 dan 6, terjadi peningkatan kemampuan siswa untuk menjawab soal dengan benar sebanyak $50 \%$ dari kondisi awal, dimana siswa belum memainkan game hanya mampu menjawab 1 sampai dengan 6 soal. Kemudian siswa memainkan game hasilnya siswa mampu menjawab 8 sampai dengan 12 soal. Oleh karena itu, dapat disimpulkan bahwa game ini berpotensi meningkatkan pengetahuan mengenai tempat bersejarah di Indonesia khususnya tempat bersejarah yang ada di Pulau Sumatera dan Pulau Jawa seperti yang ada di dalam game.

\section{UCAPAN TERIMA KASIH}

Penulis menyampaikan ucapan terima kasihnya kepada sumber pendanaan atau bantuan yang diterima, dan pihak lain memainkan peran penting dalam melaksanakan dan ketika menyiapkan naskah.

\section{REFERENSI/DAFTAR PUSTAKA}

Adiwijaya, M., Iman, K., dan Christyono, Y., 2015, Perancangan Game Edukasi Platform Belajar Matematika Berbasis Android Menggunakan Construct 2, Jurusan Teknik Elektro, Universitas Diponegoro, Semarang.

Arifin, Z, Listyorini, T, dan Fiati, R., 2015, Membangun Game Petualangan Sejarah Peninggalan Sunan Kudus Berbasis Android, Universitas Muria Kudus, Kudus.

Chua and Dyson, 2004, Applying the ISO 9126 model to the evaluation of an e-learning system, ASCILITE.

Data Pokok Kebudayaan. Diakses pada 25 Oktober 2019, dari https://dapobud.kemdikbud.go.id/

David, A.B., 2011.Mobile Aplication Testing (Best Practices to Ensure Quality). Amdocs, 2.

Hurd, D., dan Jennings, E.,2009, Standardized Educational Games Ratings: Suggested Criteria

Jeff, T., 2005, Software Quality Engineering: Testing, Quality Assurance, and Quantifiable Improvement.

Nendya, M.B., Gunanto, S.G., dan Santota, R.G., 2015, Pemetaan Perilaku Non- Playable Character Pada Permainan Berbasis Role Playing Game Menggunakan Metode Finite State Machine.

Pangestika, E.A., Aripin., dan Setyanto, D.W., 2015, Perancangan Game Edukasi Pengenalan Pakaian Adat Nusantara, Jurusan Komunikasi Visual, Universitas Dian Nuswantoro, Surabaya.

Peta budaya Indonesia. Diakses pada 25 Oktober 2019, dari https://belajar.kemdikbud.go.id/PetaBudaya

Pressman, R.S., 2002, Rekayasa Perangkat Lunak, Buku Satu, Andi, Yogyakarta

Purwaningsih, R.I., 2014, Perancangan Game Edukasi Pengenalan Tokoh Pahlawan Nasional untuk Anak Sekolah Dasar, Jurusan Teknik Informatika, Universitas Muhammadiyah Surakarta, Surakarta.

Putri Sukma, Dewi., Sanriomi, Sintaro, 2019, Mathematics Edutainment Dalam Bentuk Aplikasi Android, Triple S (Journals of Mathematics Education) 2(1). 1-11

Rahadian, M.F., Suyatno, A., dan Maharani S., 2016, Penerapan Metode Finite State Machine Pada Game The Relationship, Program Studi Ilmu Komputer, Universitas Mulawarman, Samarinda.

Rahmanto, Y., Utama, R. Y. 2018. Penerapan Teknologi Web3D Berbasis Android sebagai Media Pembelajaran Gerakan Dasar Silat - Jurnal TAM (Technology Acceptance Model).

Republik Indonesia, 2010, Undang-Undang Nomor 11 Tahun 2011 tentang Cagar

Sari, B.K., dan Sudarmilah, E., 2016, Rancang Bangun Multi Platform Edugame untuk Sejarah Khulafaurrasyidin, Program Studi Informatika, Universitas Muhammadiyah Surakarta, Surakarta.

Saputra, V., H. Darwis, D., Febrianto, E. 2020. Rancang Bangun Aplikasi Game Matematika Untuk Penyandang Tunagrahita Berbasis Mobile - Jurnal Komputer dan Informatika.

Sugiyono, 2003, Metode Penelitian Bisnis, Cetakan Kelima, CV. Alfabeta, Bandung

Sutopo, H., 2009, Pengembangan Evaluasi Pembelajaran Berbasis Multimedia dengan Flash, PHP dan MYSQL, Universitas Persada Indonesia YAI, Jakarta.

Vika, R., 2015, Perancangan Board Game Untuk Meningkatkan Pengetahuan Bangunan Sejarah di Kota Bandung, Program Studi Desain Komunikasi Visual, Universitas Kristen Marantha, Bandung.

Widyani, Y., dan Ramadan, R., Game Development Life Cycle Guidelines, International Conference on Advanced Computer Science, 2013, pp. 95-100.

Wulandari, A.D., 2012, Game Edukatif Sejarah Komputer Menggunakan Role Playing Game (RPG) Maker XP Sebagai Media Pembelajaran di SMP Negeri 2 Kalibawang, Program Studi Pendidikan Teknik Informatika, Universitas Negeri Yogyakarta. 